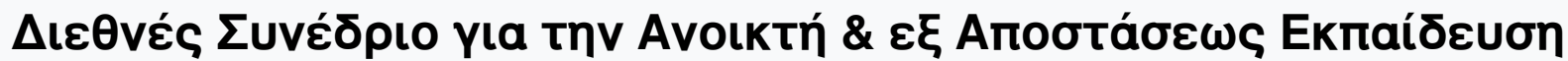

Tóp. 10, Ap. 3A (2019)

\section{ПPAKTIKA}

$10^{C}$ EYNEAPIO TIA THN ANCIKTH \& E AחCETALERI EKMAIAEYLH

를
AQHNA, 22 - 24 NOEMBPIOY 2019

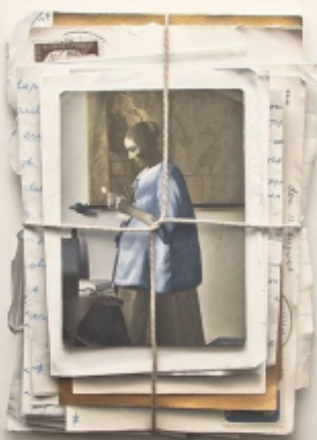

Lianopqúvovtac anó TKowoú

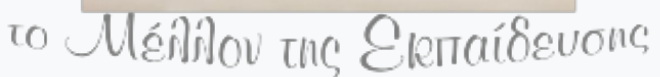

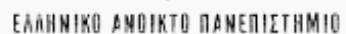

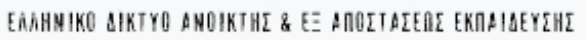

TOMOL 3, MEPOLA $\left(\begin{array}{l}\delta \\ a\end{array}\right)$

ICT and specific learning disabilities: A proposition for the use of the software Rewordify in the foreign language learning by students with reading comprehension difficulties

Panagiota Athanasiadou, Georgia Andreou, Eleni Gana

doi: $10.12681 /$ icodl. 2298 


\title{
ICT and specific learning disabilities: A proposition for the use of the software Rewordify in the foreign language learning by students with reading comprehension difficulties
}

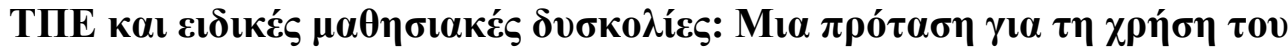

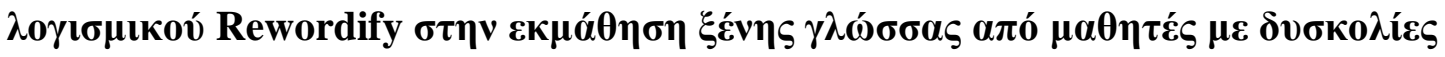

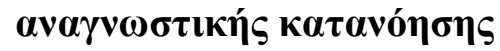

\begin{tabular}{|c|c|c|}
\hline 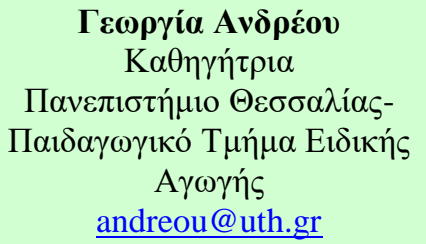 & 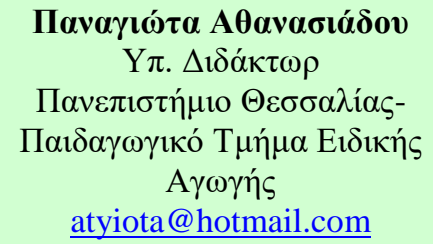 & 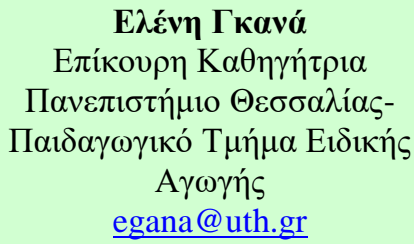 \\
\hline
\end{tabular}

\begin{abstract}
During the past few years, there has been a growing interest in the use of Information and Communication Technologies (ICT) in education. ICT has become more and more prominent in classrooms in any possible way, enabling teachers to make their lessons more interesting and effective. Furthermore, a number of studies has been focusing on the use of technology in accommodating the needs of students with special educational needs and especially of those with specific learning disabilities. It is widely accepted that technology can help those students cope with the material that troubles them. Technology becomes even more useful when we use it in foreign language learning on the part of students with specific learning disabilities, a process that entails additional difficulties for them. English, which is the first foreign language taught to students in the Greek educational system, is a phonologically non-transparent language, a fact that causes severe difficulties to students with specific learning disabilities especially in the domain of decoding and reading comprehension. In the current article, a brief review of the use of technology in education and especially in special education was attempted. The aim of the article was the utilization of an educational software in the classroom for accommodating the needs of students with specific learning disabilities in reading comprehension in English. Potential limitations were also discussed.
\end{abstract}

Key words: ICT, Rewordify, reading, difficulties, foreign language

\section{Пєрі́ $\eta \psi \eta$}

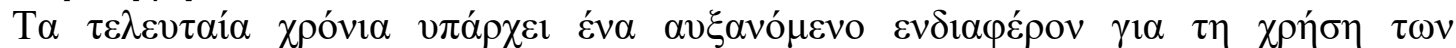

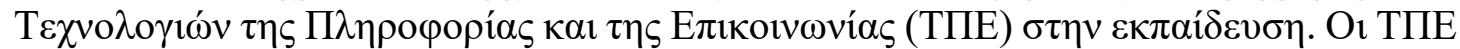

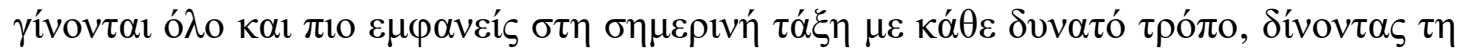

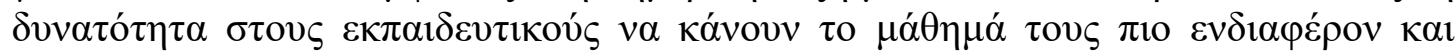

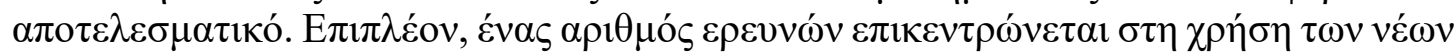

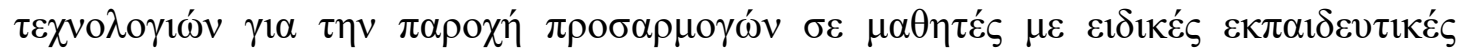

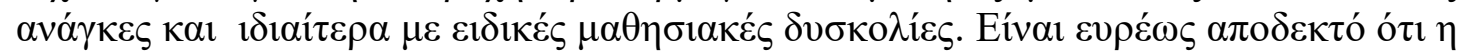

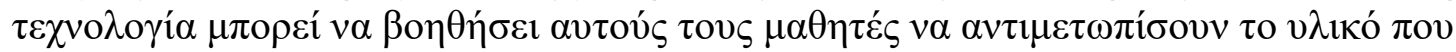

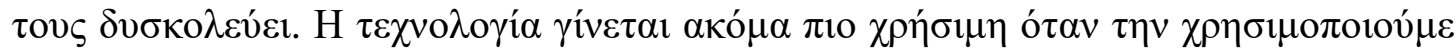

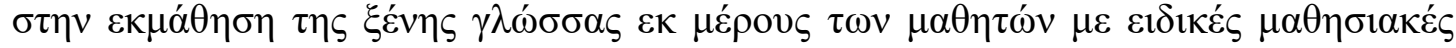




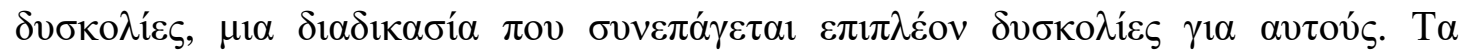

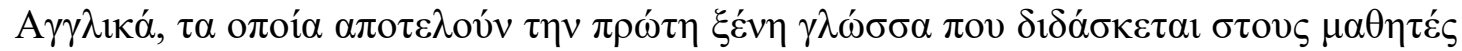

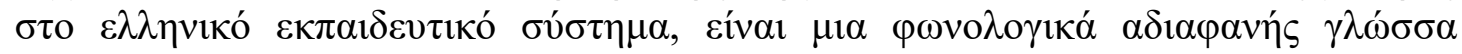

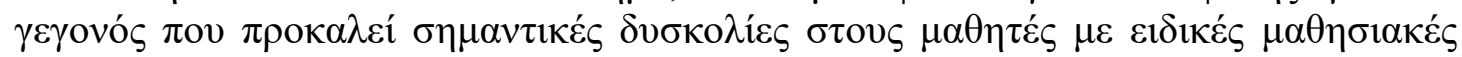

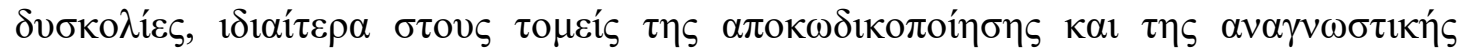

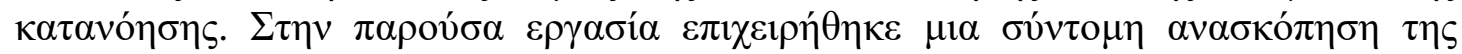

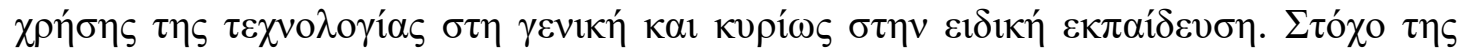

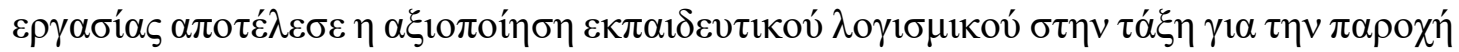

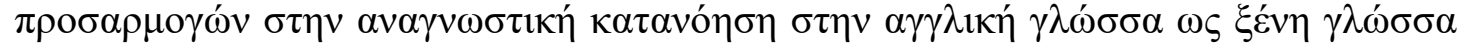

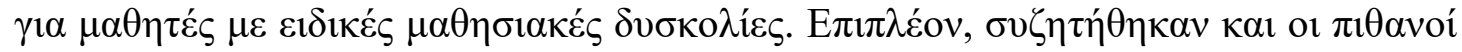
$\pi \varepsilon \rho ı \rho ı н$ нí.

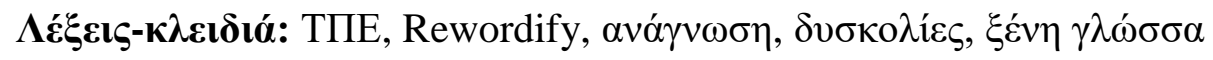

\section{Introduction}

The rapid expansion of technology and technological devices, within the last decades, has defined our way of living, working and learning. This phenomenon is even more evident in the youth who are defined as digital natives, since they are born in the era of technological advancement and they learn how to use technology from the very beginning of their lives (Gu, Zhu, \& Guo, 2013). This knowledge demands from people that come in contact with the youth to know and take advantage of technology in order to attract their interest. Keengwe, Schnellert and Mills (2012) support the significance of technology in the increase of students' motivation during the educational procedure.

Costley (2014) states that technology keeps students more engaged, enables them to retain information more easily and promotes interaction into a meaningful context. The first important change that was introduced to schools were computers, tablets and interactive whiteboards aiming at rendering the lesson more interactive, easier to understand and more oriented to education outside the classroom (Eady, \& Lockyer, 2013). Following the equipment, a number of applications and tools have been used to support the teaching procedure.

There is a wide variety of applications and technological environments on which somebody can work and prepare material for his students. Some of them that are used in teaching and foreign language teaching will be briefly presented below. The most popular environment in which students work collaboratively are online classrooms which allow them to discuss ideas, create wikis (texts with information written collaboratively), write blog entries (Eady, \& Lockyer, 2013) on issues they are interested in, participate in online classrooms through skype with direct visual presence or in digital classrooms with no direct presence, such as Moodle, Edmodo and Google class. Moving on to teaching per se, there are a number of e-books and interactive ebooks, especially as far as foreign language teaching is concerned, which present all the material of the written book as well as additional exercises based on the material assigned, e-games and animated features (Schugar, Smith, \& Schugar, 2013). Via an ebook, it is quite easy to customize the font size, write on the texts, zoom on particular extracts (Lucia, 2001) and use existing hyperlinks (Wong, Liong, Lin, Lower, \& Lam, 2011); changes that offer differentiation of material presentation to students. 
Furthermore, another important multisensory technological tool is videos which through authentic material combines pictures and sound that helps students with poor comprehension skills match words and images so that they understand the information presented (Cakir, 2006). As for the display accommodations, there are also software such as the Classmate Reader and Assistive Software (Floyd, \& Judge, 2012· Lange, McPhillips, Mulhern, \& Wylie, 2006) which additionally offer the option of read aloud accommodation to aid students in the decoding of challenging words.

Moreover, applications like Kahoot and Quizziz are widely used in today's classrooms; both of them being online test making applications through which students can participate in an online multiple choice battle by just pressing the correct button on their cell phones. Assessment in that way becomes indirect, interactive and fun (Jaffri, \& Talib, 2017). Additionally, there is a number of applications which enhances writing skills and promotes collaborative work such as Storybird and Storyjumper, as well as applications for creating comic strips that enhance writing and organizational skills, since they present an environment where students choose their own background pictures, titles, exact words and heroes so as to create their own story (Menezes, 2012).

Apart from the integration of technology in the learning procedure, the last few decades other issues have arisen. A significant change was the urgent need to integrate students with specific learning disabilities in the typical classrooms and accommodate their educational needs (Engstrom, 2005). Technology being a means of raising students' motivation (Costley, 2014), improving the retention of material, catering for various learning profiles and needs (Riga, Andreou, \& Anastasiou, 2017) and allowing students to self-regulate their learning (Fisher, \& Baird, 2005) became the key element of accommodating various educational needs. Furthermore, during the last ten years, there has been an increasing interest in assessment accommodations for students with specific learning disabilities. Those students face problems in several domains depending on their learning profile. Consequently, teachers try to accommodate the needs of this group of students during the teaching procedure (intervention programs) as well as the assessment procedure (test accommodations) (Thurlow, Lazarus, Thompson, \& Morse, 2005), a domain to which technology is significantly helpful.

The aim of the article is to briefly discuss the challenges faced in reading and reading comprehension by students with reading comprehension difficulties and to thoroughly present the use of an educational software in the light of educational support to students with reading comprehension difficulties in English as a foreign language. Both the strengths of the software and possible limitations are discussed.

\section{Students with specific learning disabilities and reading comprehension difficulties}

Learning disabilities are defined as an unexpected difficulty in the process of learning that is not compatible with the intellectual capacity of a person (Gersten, Fuchs, Williams, \& Baker, 2001). A common finding in the majority of researches is the severe difficulties in reading comprehension that students with learning disabilities face (Kavale, \& Reece, as cited in Gersten et al., 2001). Reading comprehension is a complex procedure which significantly affects one's academic and social development and demands the automaticity of "lower" cognitive processing skills, such as decoding (Helland, \& Kaasa, 2005) and more demanding cognitive skills (Kuhn, Schwanenflugel, \& Meisinger, 2010), such as self-regulation techniques (Dermitzaki, 
Andreou, \& Paraskeva, 2008). The situation is even more challenging for students with learning disabilities and especially reading difficulties, rendering reading comprehension a difficult and dissuading task (Torgesen, 2006). Apart from reading difficulties, students may present problems in domains such as memory span, vocabulary retention, inference making, self-regulation techniques (Zimmerman, 2002) and time management (Shaywitz, \& Shaywitz, 2005). All the aforementioned negatively affect reading comprehension in multiple ways, thus rendering both its teaching and assessing challenging for teachers.

Focusing on the assessment procedure of students with learning disabilities and more specifically of those who face reading comprehension difficulties, it is evident that underperformance in this skill is more intense, since a standard test may not be accurate in the depiction of their knowledge (Andreou, Athanasiadou, \& Tzivinikou, 2019). Consequently, during the past few years there has been an increasing experimental interest in the test accommodations during the assessment of students with specific learning disabilities, one of the most frequent being the use of technology (Schneider, Gong, \& Egan, 2016). In the following sections of this article, the educational software Rewordify is presented and several propositions on its use for teaching and assessing reading comprehension of students with reading difficulties are made.

\section{The educational software Rewordify and propositions for its use in the foreign language classroom for students with reading difficulties}

\section{Description of the software}

There are a number of applications and software which can be used by teachers during the teaching and assessment procedure so that they help students with and without learning disabilities cope with the material better and enhance their competence in various skills. In this section, we will present a free online educational software which aims at facilitating reading comprehension.

Rewordify is a software that applies only to the English language, consequently it can be used for native speakers of English facing reading difficulties and students that learn English as a foreign language. Based on the difficulties English poses to students as far as reading comprehension is concerned, Rewordify aims at facilitating two of the basic aspects of reading comprehension, decoding and vocabulary. The core function of Rewordify is to choose a text and paste it into the box that appears on the home page when you press the following link https://rewordify.com/. When you paste the text in this box, you press Rewordify and you can see that some of the difficult words of the text have been paraphrased so that they facilitate the comprehension of the text. In this procedure there are important settings you can change. When you scroll down the page the option "Settings" appears at the bottom. Through settings you can make three important changes in the appearance and processing of the text you want to rewordify.

First, you can choose the display mode that applies to you. There are five choices; rewording hard words and clicking on them to see the rewordified word, not rewording words but tapping to see definitions, displaying initial word and rewordified one inline, displaying original and rewordified word in two columns and displaying original text with a vocabulary column of the words that you rewordified next to it. The second 
setting refers to the level. There are six levels of difficulty which determine the words that you want to rewordify in terms of number and difficulty. If somebody raises the level of difficulty it means that only the hardest words are to be rewordified whereas as you lower the level of difficulty almost all the words that are considered difficult will be rewordified with descriptive definitions or words that tend to be simpler as you move through the various levels of difficulty. The last setting refers to highlighting mode. Rewordified words are underlined in the target text. Readers can choose the colour that works best for them or even choose a simple underlining or no marking at all.

When the readers finish with the settings they have two options. Either they choose from a pool of classic literary texts to practice their reading comprehension or they can find the text they want or the URL and paste it into the box to be rewordified. By rewordifying a text, apart from the changes in hard words, there is also the option of listening to the words that were challenging to you. The software has a read-aloud option for the words that are rewordified, so that it facilitates decoding difficulties.

Apart from being self-study software, which increases students' self-regulation techniques and offers them possibilities to practice at home, Rewordify is a useful tool for teachers as well. Teachers can paste texts in the software for teaching or assessing purposes. During the teaching procedure, students can comprehend the rewordified text, discuss it with the teacher and be assigned the difficult words and their rewordified equivalent in context, which helps them retain what they have learnt. Moreover, there is an option, when you create a free account, to save and create your own vocabulary and prepare quizzes and other activities for your students to practice the words that were challenging to them.

As far as assessment is concerned, Rewordify can be a useful tool for teachers to assess students with reading difficulties. Based on the existing literature, technology is one of the accommodations, especially software and applications, which are used to enhance the accuracy of the performance of students with specific learning disabilities. Rewordify offers all the options that have been proven to aid students perform according to their potential. Teachers can paste the text they want assess and choose the corresponding settings. A significant option that makes Rewordify a reliable assessment tool is the fact that the teachers can choose the words that they think they need to be rewordified and even use their own definitions so that they ensure the level is appropriate for students, since the standard options of software are not always applicable to every class and student. Students also have the chance to listen to the challenging word to solve any decoding difficulties that may obstruct them from understanding it. A good many researchers such as Dolan, Hall, Banerjee, Chun and Strangman (2005) and Floyd and Judge (2012) have proven through experimental studies the beneficial effects of read-aloud accommodation through technology for the reading comprehension of students with reading difficulties. All the aforementioned options that this software offers render Rewordify a software that covers the needs of students with reading difficulties, ensuring at the same time the reliability of their results in the accommodated reading comprehension assessment.

Despite the benefits that Rewordify presents, there are also limitations that need to be considered. First of all, as it happens with any other software it is impossible to cater for everyone's needs and competence. In the software Rewordify an effort has been made to rewordify words as accurately as possible into the given context. However, this is not always possible especially when it comes to academic texts in which particular 
jargon is used. Moreover, quizzes and exercises can be created only for separate words to be practiced and not for the whole text. In other words, students cannot have a full reading comprehension exercise in the body of the software so the teacher has to give the reading comprehension questions separately, typed or in another file accessible to the computer the students use. Moreover, Rewordify does not give the option of reading aloud the whole text, as was the case in previous research studies that used read-aloud accommodations, but it is restricted to the words that have been rewordified, thus limiting the beneficial effects that read-aloud accommodations offer. Finally, as far as technical issues are concerned, as a technological facility it is essential that students be provided with laptops or tablets so that they can easily use the software, which means that it is a rather expensive investment for an educational institution that does not already have this equipment.

All in all, the advantages of this free online educational software outweigh the disadvantages. The easiness of use and the fact that it does not need to be installed in a computer but still keeps record of students' personal vocabulary and performance renders it ideal for teachers who are not specialized in ICT and for students who need to strengthen their self-studying skills.

\section{Educational scenario}

As it was previously mentioned, Rewordify can be used without any formal training by both students and teachers. In the following paragraphs, an educational scenario of its use is presented so as to better comprehend its utilization in classroom. The following planning refers to the skill of reading comprehension of students with reading comprehension difficulties attending the sixth class of Primary school.

At the beginning of the lesson, the teacher projects on the whiteboard a text from classic literature, available in the software. According to the level of the class and their previous knowledge, the teacher chooses one of Aesop's Fables. Students are familiar with the Fables as they have been exposed to them throughout their education. From the option at the left top of the page, the teacher chooses the option "classic literature""Aesop's Fables" and selects the "Fox and the Goat", which was not known to the students, so as to prevent any previous knowledge on the content. By choosing the text, it immediately appears in its Rewordified version. The settings are selected by the teacher, default option -5 rewordified words, original and rewordified word inline marked with different colour.

The lesson starts by the reading of the text so as to speculate on any decoding difficulties. There is the option of listening to the words that are rewordified so as to correct any false decoding. Students listen to the difficult words and then repeat after the read aloud of the software. Finally, students reread the text. Following the reading, students are asked to narrate the story by using their own words and then answer to oral reading comprehension questions. There is no need to explain difficult words, since they are replaced by words that correspond to students' level and allow them to reach a successful comprehension of the text despite their difficulties. In this way, the teacher can also assess the competence in comprehension after the use of the software.

Following the brief reading comprehension exercise, the teacher hands out worksheets that are prepared by the software for the students to practice the words that were rewordified. The worksheets include matching exercises, clozes and definition exercises. The teacher has also prepared a worksheet for homework in the software and 
printed it out for the students. The software gives the option of creating your own worksheets by adding any other word that you want in the worksheet prepared for the text that you have rewordified. The teacher has also created a cloze with both challenging words and words that were not rewordified for students' autonomous practice at home. After practicing the new vocabulary through the exercises, the teachers provides students with an open-ended reading comprehension exercise that demands more detailed comprehension, so that they use their new vocabulary knowledge in context. Finally, the teacher urges the students that are using the software at home to $\log$ in and choose the option of "learning sessions" in which they autonomously practice the words from the assigned text, having also the chance to keep track of their progress through the scores and the charts provided by the software. In the next lesson, students are assessed through the software by completing a gap-filling exercise based on the assigned vocabulary.

\section{Conclusion}

Reading comprehension is a very challenging domain due to the complexity of skills that a student must acquire (Kuhn, Schwanenflugel, \& Meisinger, 2010). The aforementioned causes a good many difficulties to students without and especially with reading difficulties. An aggravating factor is the phonology of each language which makes it easier to decode it or not. English, a phonologically non-transparent language, renders reading and reading comprehension a difficult procedure since students find difficulties even in the lower processing skills, such as decoding (Helland, \& Kaasa, 2005).

ICT in education is a new field that rapidly changes due to the increasing rate of development in technological devices, software and applications. A number of applications have been used in the teaching and assessing procedure both in general and special education without however being always successful. A lot of problems such as the lack of funding and expertise have prevented teachers from knowing and taking advantage of the utility of technology in education. Among the variety of software and apps that are used in order to raise students' motivation and performance in various skills (speaking, listening, writing, self-regulation), we have chosen to present a free educational software for the teaching and assessing of reading comprehension in the English language named Rewordify and support its integration in the educational procedure.

Rewordify offers a variety of options that can be used both in the teaching and the assessing procedure of reading comprehension, a challenging skill for speakers/learners of English as a foreign language, especially for those with specific learning disabilities. It is a software that does not need financial supplies to be available and it is easy to be used by both teachers and students, a fact that makes it an asset in every educational institution, compared to other apps and software that demand specialized knowledge, financial contribution and are not easily used by students without the constant support of their teachers.

Through its use in the educational practice, the students have the opportunity to facilitate their reading comprehension without the constant intervention of the teacher by encountering word equivalents that match their educational level. Following the benefits to comprehension, students have the chance to practice the new vocabulary of 
the text through various exercises that are ready-made or prepared by their teachers, as well as practice the words they are assigned through their personal account at home. This option allows teachers to have plenty of material on the assigned vocabulary and promotes students' autonomous learning. Finally, students are also supported in the decoding of challenging vocabulary so that they learn both its pronunciation and meaning, two elements that constitute the knowledge of words in the mental lexicon of students. All the aforementioned elements allow students with specific learning disabilities to encounter a text the comprehension of which is not hindered by the lack of decoding accuracy and vocabulary on their part and to come in contact with new vocabulary both visually and orally in various contexts (text and exercises) with the aim of achieving its retention.

\section{References}

Andreou, G., Athanasiadou, P., \& Tzivinikou, S. (2019). Accommodations on reading comprehension assessment for students with learning disabilities: A review study. Psychology 10(04), 521-538. Doi: 10.4236/psych.2019.104034

Cakir, I. (2006). The use of video as an audio-visual material in foreign language teaching classroom. Turkish Online Journal of Educational Technology-TOJET, 5(4), 67-72. Retrieved from https://eric.ed.gov/?id=EJ1102619

Costley, K. C. (2014). The positive effects of technology on teaching and student learning. Arkansas Tech University.

Dermitzaki, I., Andreou, G., \& Paraskeva, V. (2008). High and Low Reading Comprehension Achievers' Strategic Behavior and Its Relation to Performance in Reading Comprehension. Reading Psychology, 29, 471-492. https://doi.org/10.1080/02702710802168519

Dolan, R. P., Hall, T. E., Banerjee, M., Chun, E., \& Strangman, N. (2005). Applying Principals of Universal Design to Test Delivery: The Effect of Computer-Based read Aloud on Test Performance of High School Students with Learning Disabilities. Journal of Technology, Learning, and Assessment, 4, 4-32. https://ejournals.bc.edu/ojs/index.php/jtla/issue/archive

Eady, M., \& Lockyer, L. (2013). Tools for learning: Technology and teaching. Learning to teach in the primary school, 71 . Retrieved from https://ro.uow.edu.au/cgi/viewcontent.cgi?article=1413\&context=asdpapers

Engstrom, E. U. (2005). Reading, writing, and assistive technology: An integrated developmental curriculum for college students. Journal of Adolescent \& Adult Literacy, 49(1), 30-39. Retrieved

from https://www.pioneerschools.org/cms/lib/NY19000288/Centricity/Domain/125/AT_reading_an d_writing.pdf

Fisher, M., \& Baird, D. E. (2005). Online learning design that fosters student support, self-regulation, and retention. Campus-wide information systems, 22(2), 88-107. https://doi.org/10.1108/10650740510587100

Floyd, K. K., \& Judge, S. L. (2012). The Efficacy of Assistive Technology on Reading Comprehension for Postsecondary Students with Learning Disabilities. Assistive Technology Outcomes and Benefits, 8, 48-64. https://www.learntechlib.org/p/114207/.

Gersten, R., Fuchs, L. S., Williams, J. P., \& Baker, S. (2001). Teaching reading comprehension strategies to students with learning disabilities: A review of research. Review of educational research, 71(2), 279-320. Doi: 10.3102/00346543071002279

Gu, X., Zhu, Y., \& Guo, X. (2013). Meeting the "digital natives": Understanding the acceptance of technology in classrooms. Journal of Educational Technology \& Society, 16(1), 392-402. Retrieved

from https://www.researchgate.net/profile/Xiaoqing_Gu2/publication/279552001_Meeting the_Dig ital_Natives_Understanding the acceptance_of technology in classrooms/links/58c9e44492 
$\underline{851 \mathrm{c} 4 \mathrm{~b} 5 \mathrm{e} 6 \mathrm{c} 9 \mathrm{ef} 0 / \mathrm{Meeting} \text {-the-Digital-Natives-Understanding-the-acceptance-of-technology- }}$ in-classrooms.pdf

Helland, T., \& Kaasa, R. (2005). Dyslexia in English as s Second Language. Dyslexia, 11, 41-60. https://doi.org/10.1002/dys.286

Jaffri, H., \& Talib, R. (2017). Using Gamification to Increase Students' Motivation: Our Experience in Teaching Research Methodology Class. In: Proceedings of the International Conference on the scholarship of teaching and learning, $4^{\text {th }}-5^{\text {th }}$ April 2017 (p. 53-61). UUM EDC Hotels \& Resorts, Sintok, Kedah, Malaysia.

Keengwe, J., Schnellert, G., \& Mills, C. (2012). Laptop initiative: Impact on instructional technology integration and student learning. Education and Information Technologies, 17(2), 137-146. Doi: 10.1007/s10639-010-9150-8

Kuhn, M., Schwanenflugel, P., \& Meisinger, E. (2010). Aligning Theory and Assessment of Reading Fluency: Automaticity, Prosody, and Definitions of Fluency. Reading Research Quality, 45, 232-253. https://doi.org/10.1598/RRQ.45.2.4

Lange, A. A., McPhillips, M., Mulhern, G., \& Wylie, J. (2006). Assistive Software Tools for SecondaryLevel Students with Literacy Difficulties. Journal of Special Education Technology, 21, 13-22. https://doi.org/10.1177/016264340602100302

Lucia, S. (2001). E-books and their future in academic libraries. D-Lib Magazine, 7 (7). Doi: 10.1045/july2001-snowhill

Menezes, H. (2012). Using Digital Storytelling to Improve Literacy Skills. International Association for Development of the Information Society.

Riga, A., Andreou, G. \& Anastassiou, F. (2017). Enhancing the language literacy skills of children with Specific Learning Difficulties; a review on the use of technology and the application of innovative teaching methods. European Journal of Educational Sciences, 4(3), 13-18. doi: 10.19044/ejes.v4no3a2

Schneider, C., Gong, B., \& Egan, K. (2016). Testing Accommodations for Students with Dyslexia: Key Opportunities to Understand Student Thinking . Retrieved from

https://www.nciea.org/library/testing-accommodations-students-dyslexia-key-opportunitiesunderstand-student-thinking

Schugar, H. R., Smith, C. A., \& Schugar, J. T. (2013). Teaching with interactive picture e-books in grades K-6. The Reading Teacher, 66(8), 615-624. Doi:

10.1002/TRTR.1168

Shaywitz, S. E., \& Shaywitz, B. A. (2005). Dyslexia (Specific Reading Disability). Biological Psychiatry, 57, 1301-1309. https://doi.org/10.1016/j.biopsych.2005.01.043

Thurlow, M., Lazarus, S., Thompson, S., \& Morse, A. B. (2005). State Policies on Assessment Participation and Accommodations for Students with Disabilities. The Journal of Special Education, 38, 232-240. https://doi.org/10.1177/00224669050380040401

Torgesen, J. K. (2006). Recent Discoveries from Research on Remedial Interventions for Children with Dyslexia. In M. Snowling, \& C. Hulme (Eds.), The Science of Reading: A Handbook. Oxford: Blackwell Publishers.

Wong, K., Liong, C., Lin, Z. X., Lower, M., \& Lam, P. (2011). EBooks as teaching strategy-preliminary investigation. In G. Williams, P. Statham, N. Brown \& B. Cleland (Eds.), Changing Demands, Changing Directions. Proceeding ASCILITE Hobart, $4^{\text {th }}-_{-7}^{\text {th }}$ December 2011 (p. 1343-1352).

Zimmerman, B. J. (2002). Becoming a Self-Regulated Learner: An Overview. Theory into Practice, 41, 64-70. https://doi.org/10.1207/s15430421tip4102_2 http://mathedseminar.pbworks.com/w/file/fetch/94760840/Zimmerman\%20-\%202002\%20$\% 20 \mathrm{Bec}$ ining $\% 20 \mathrm{a} \% 20$ SelfRegulated\%20Learner\%20An\%20Overview.pdf 